\title{
The impact of internet on ITEM: educational management in preparation for the future
}

\author{
A.C.W. Fung \\ Department of Education Studies, Hong Kong Baptist University \\ Kowloon Tong, Hong Kong \\ Phone: (852)-23395679 \\ Fax: (852)-23397894 \\ e-mail: alexfung@hkbu.edu.hk \\ S.W. Pun \\ Hong Kong Institute of Education \\ Grantham Campus, 42 Gascoigne Road, Kowloon, Hong Kong \\ e-mail: swpun@gc.ied.edu.hk
}

\begin{abstract}
Schools of the future will no longer be islands on their own. The common saying that "it takes a village to educate a child" might have to be re-worded as "it takes the globe to educate a child"! The world is shrinking, metaphorically speaking, in space and time as IT advances. Recent studies suggest that there are now in USA alone more than 100,000 E-mail accounts on state educational networks, and approximately 600,000 networking students in private and grassroots initiatives. With the expansion of global networking, educators have many pressing issues to reconsider. How different, for instance, will the schooling process become in the next decade? This paper is no attempt to give any positive answer. It is an attempt instead to give a snapshot of the current state of affairs on the Internet in connection with education and ITEM in particular. Prospects are discussed and questions are raised. The intent is to generate interest from participants in the '2nd IFIP International Working Conference on ITEM' in developing a vision for which educational administrators need to prepare.
\end{abstract}

\section{Keywords}

Educational management, communications, future developments, infrastructure, internet, networks, visions 


\section{INTRODUCTION}

Nineteen ninety-six will be dominated by the Internet. This is the opinion of the USbased research company, IDC, in a recent report in Asia Computer Weekly, 1996. This report also forecasts for 1996 that 80 percent of PC shipments will be to the home market and that the number of on-line users will rise to more than one billion. Recent studies also suggest that there are now in USA alone more than 100,000 E-mail accounts on state educational networks, and approximately 600,000 networking students in private and grassroots initiatives (Itzkan, 1995). Expert opinion estimates that by the end of the decade, there will be 3 to 5 million networking students in the U.S. With the expansion of global networking, educators have many pressing issues to reconsider. How different, for instance, will the schooling process become in the next decade? What are the impacts of the Internet on teaching and learning, and on educational management? This paper is not an attempt to give a definitive answer. It is an attempt instead to give a snapshot of the current state of affairs on the Internet in connection with education broadly, and ITEM in particular.

\section{THE TECHNOLOGICAL REVOLUTION}

Technological advances in computing and telecommunication have in the past few years set off at an unprecedented pace developments in information networking and sharing. New ideas and applications are generated everyday, if not every hour, around the world. New terminologies are created that soon become old - Internet, World Wide Web (WWW), Emailing, Video conferencing, high speed RAS (remote access services), Integrated Services Digital Network (ISDN), modems, multimedia, hypertext, Internet phone, WebPC, WebTV, cable modems, etc. While this list will continually lengthen, there is a convergent view that speed and price in datacomm is no more the major issue and the information network will soon be penetrating into homes. The US-based cable television industry, for example, will begin offering datacomm on cable television channels to home-users with cable modems to enable access at speeds up to a thousand times faster than the $28.8 \mathrm{kbits} / \mathrm{s}$ of the analog telephone lines (Asami \& Kato, 1996). It is asserted that this US-based cable television network is emerging as the ultimate home information infrastructure, mainly because about 96 percent of all households can subscribe to cable television in USA.

In this information era, schools can choose to react passively and reluctantly to technological changes, or they can proactively learn to harness the power to the benefit of their pupils. Taking the latter stance, for example, the Lake Oswego District in Oregon has a vision for the 21 st century "to provide a learning environment in which the use of technology is just as natural to students as the use of a pen or pencil is to most adults" (Lake Oswego District Web Server, 1996).

\section{THE IMPACT ON BOOKS AS INFORMATION VEHICLES}

Books, whether of reference, non-fiction, or novels, have been around with us for years. We have all been accustomed to the traditional way of obtaining information through them and the paper medium. We all know the good things about such vehicles: they are compact and cheap, they are quite accessible and easy to carry, and they can be reproduced conveniently. We can write notes on them, and we certainly know how to browse our way through books. However, searching with an index or table of contents in a book is somehow quite limited. Finding a specific piece of information within a book can be very tedious, or sometimes impossible although the data is there. 
Intrinsically, information is confined to each individual book. When more related information is needed and libraries or archives are taken into consideration, books are not economical in terms of time, costs and space. Costs of keeping paper documents in libraries increases in this information age. Maintenance is difficult and expensive, especially when the documents become dated. And, perhaps most importantly from a publisher's point of view, writings on papers are static and their revisions are costly.

From a user's point of view, knowledge and information are best to be up to date and meeting their needs. When a certain piece of information falls short of users' expectation or satisfaction, it would be ideal to have further or related information immediately available on demand. It would also be much more useful and attractive if such information is not just in plain text, but in different forms of sound, pictures, and videos, as the user desires. Such hyperlinking and multimedia capabilities are, of course, beyond the capabilities of the traditional book, but are realities in electronic ones, and on web-pages now available on the Internet. Besides, there is no limit to the number of users simultaneously reading the page, and there is no problem with deterioration of the paper!

Books and papers will not of course be abandoned. But they will not be the dominant source or vehicle of knowledge and information as in the past. They can only coexist with their electronic counterpart in future.

\section{THE IMPACT ON TEACHING \& LEARNING}

In the course of preparing for this paper, we have visited a number of educational Websites on the Internet. The number of educational bodies getting onto Internet is definitely multiplying, including government departments, research institutes, commercial vendors, universities, and schools. A few emerging uses of Internet are identifiable for educational purposes:

- informing the public;

- providing research findings;

- providing resources;

- promoting image;

- providing support to teachers;

- $\quad$ providing support to pupils;

- providing support to school administrators and managers.

The wealth of information now available on the Internet in these seven areas, though not necessarily categorized as such, is simply amazing. In fact the number of resources on the WWW has grown at such an incredible rate that some Websites are specially dedicated to provide meta-indexes (indexes to other indexes) for educators. Examples of these meta-indexes are found in the USA at websites such as the "http://www.yahoo.com/Education/ K_12/", or "http://hillside.coled.umn.edu/others. html"; and in the UK such as the "pathways Home Page' of "http://www.ifl.rmplc. co.uk/".

Apparently there is also the converging opinion from writings in different Websites (e.g. NCREL, Horizon, EdWeb) that the Internet Age will open up a scenario in teaching and learning significantly different from the traditional process: 
1. In allowing teachers and pupils immediate connection to the outside world, the Internet has broken down in some sense, if not entirely, the boundary of the traditional classroom;

2. Collaborative teaching and learning, between schools and external partners, becomes feasible at the district, national, and international levels;

3. Students can learn by doing in a more authentic sense, using real life situations and simulations at times;

4. In becoming both a publisher and a browser on the Internet, as simple as just joining a discussion group with emailing, pupils are learning not just from their classroom teachers but also from many others.

We all accept that active and expressive learning means a shift from teachers' traditional information-giving to pupils' participation in information-gathering, interpretation and use. Nothing in history has provided a medium with power comparable to that of the WWW for this purpose. Wallis (1995) has described the wondrous things that occur at the Dalton School in New York City and the way it is using technology " to change the traditional roles of the teacher as oracle and the student as passive receptacle for hand-me-down knowledge".

"The Internet provides a vehicle for teachers" says Giordano (1996), "to create highperformance learning environments through which the goals of the various dimensions of schooling can be accomplished. Through resources available via the Internet, students may be provided opportunities to engage in authentic, challenging activities. Teachers can set meaningful, challenging activities as the center of instruction. Classroom approaches that support such a paradigm might include collaborative learning, heterogeneous groupings, teacher as facilitator, performance-based assessment, peer-topeer mentoring, multidisciplinary curriculum, interactive modes of instruction, student exploration, and extended blocks of time." (ibid: 360)

The Internet will not only change classroom processes, it will also radically change pupils' learning when an ultimate home information infrastructure is in place. In the commercial arena, many companies are already marketing their products and services on a home page. The Web technology has opened a new channel for direct sales to customers. To-day, electronic publishers are selling thousands of edutainment CDROM titles to families with after-sales services and support (e.g. Microsoft's Encarta and Bookshelf 96-97). Tomorrow, such sales will not be just edutainments. The IFL (Internet for Learning) pages at the Rmplc Website in UK is but one example, among many existing sites around the world and numerous more to come, competing to provide learning materials to pupils and students directly. The spectrum of subject contents, and their design and attractiveness to pupils, will be beyond the competition of the curriculum in any single school. Such knowledge providers on the Internet are definitely keen to take a share in education that has been dominated by schools for centuries! 


\section{THE IMPACT ON 'SCHOOLING'}

In 'Planning for the 21st Century', the Lake Oswego District (1996) declares:

"We recognize the learning environment is tied to the real world, that we serve a wide variety of learners, and that learning extends beyond the traditional time and space concepts of School."

We have also described in the above section that our pupils, sooner or later, will be acquiring their own communication links for exploring topics beyond the boundaries of the traditional concept of School. While access to subject experts (teachers) and resources are limited by time and space at school, pupils in future (some already now) studying at home, or in a library, or any place with Internet connection can quickly access learning resources at any hour of the day. This raises a fundamental question then of what 'Schooling' is for? When the school is no longer the only place to acquire knowledge and information, is it where pupils go for socialization? for physical development? for intellectual group interaction? for learning how to learn? for learning how to think? for learning how to communicate? for learning how to create? These are questions that we would like to seek answers to.

Education cannot stay isolated from the electronic world. The entire educational system, from K-12 to universities, will most likely be re-engineered in the Internet age. We attempt to present in Figure 1 such a transformation. In the traditional system, teachers and students interact mostly within a school which has linkage to publishers and libraries. Such subsystems work within the rather tight boundary of a single nation with a certain cultural environment. The whole system is often under government control of varying degrees. In the 'Internet Age', students are more detached from a single school and the teachers therein. They are opened to more opportunities of interacting directly with other schools and with other 'knowledge providers' on the Internet. These organisations possibly will have their own intranet (see below) boundaries while working under a multi-national and multi-cultural environment. Government control over these subsystems will become much looser than that of today.

In view of such a transformation, there are three related issues educators have to reconsider:

\section{Empowering the students?}

The key characteristic of Web technology is its ability to shift to the users the control of information flow from the information provider. When students have the pathway easily to access what information or instruction materials they prefer, as well as choose when they want to have them, no single school or text-book publisher can dominate or confine anymore the students' learning style or contents. Students are empowered in their learning on the one hand, but just the thought of it could be threatening to many teachers on the other.

\section{School as a knowledge broker?}

Web technology has made both publishing and retrieval of information easily accessible to many. What will not be easy is finding the relevant information that is created in this loosely controlled and independent environment of the Internet.

The school, as a curriculum planner and a gatekeeper, might possibly have to take up in future an additional role - serving as a kind of 'knowledge broker'. Teachers will probably have to shortlist not only books for students to read, as they do now, but also educational Websites to be visited. 


\section{The Traditional System:}

Regional boundary

Single nation, limited cultural environment, government controlled

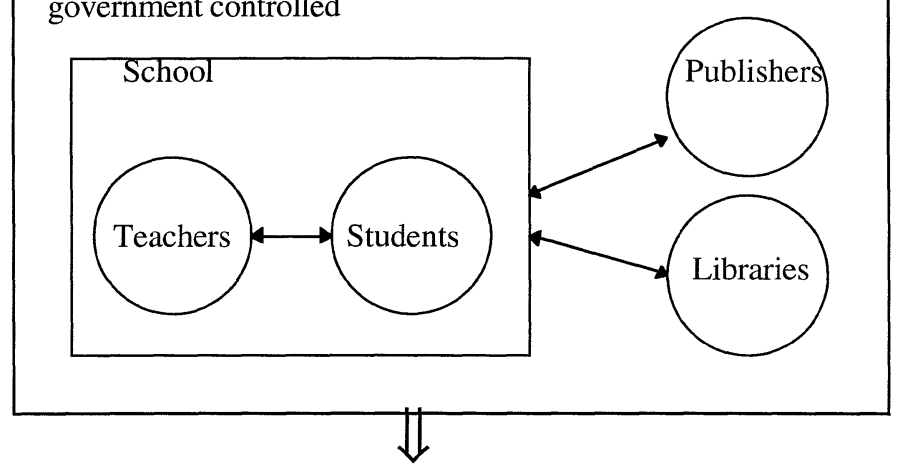

\section{The Paradigm Shift:}

Internet boundary

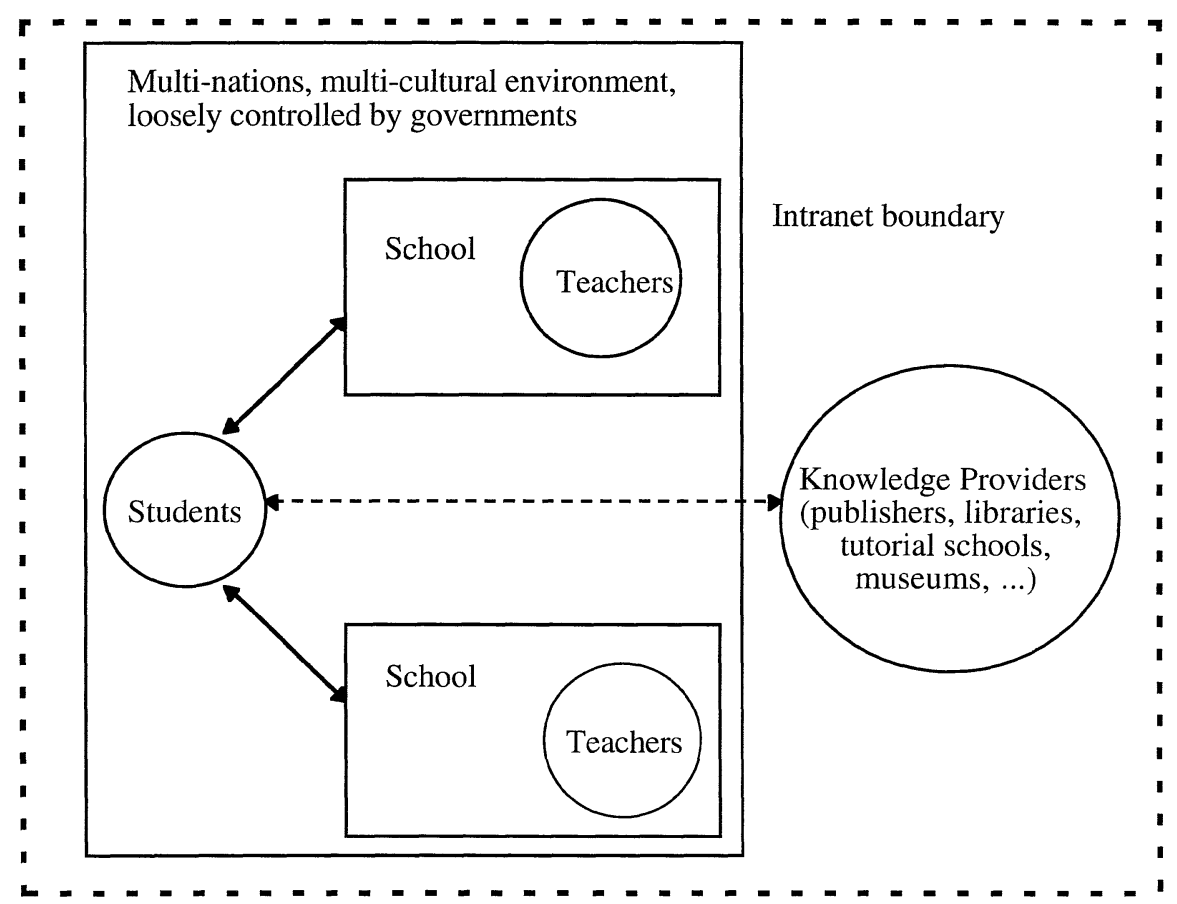

Figure 1. 'Schooling' in the Internet Age. 


\section{A controlled anarchy?}

Internet is anarchic in that it is accessible by anyone anywhere in the world and anyone anywhere can publish anything. Without proper management, the Internet could become a potential threat to the well-being of a school and its pupils when they are internetconnected. In the business and IT sectors, the concept of 'Intranet' is currently evolving (Amdahl Coporation, 1995). This is the implementation of Internet technologies within a corporate organization which can be applied in an individual school. Instead of directly connecting the school library or classrooms to the global Internet, access first goes on an Intranet within the school. The implementation is performed in such a way as to permit only communication with selected and authorised Websites of educational value to students and teachers. In such a controlled anarchy, anyone on the Intranet can still access or publish anything and benefit educationally from the Internet.

\section{CONCLUSION}

Schools of the future will no longer be islands on their own. The common saying that "it takes a village to educate a child" might have to be re-worded as "it takes the globe to educate a child"! Educational administrators conscious of the rapid developments in the field of IT, and in particular of Internet, will probably agree with this. The world is shrinking, metaphorically speaking, in space and time as IT advances.

Today, technology is not the issue. It is a matter of hardware performance (costs dropping and speed increasing) to realise what we have discussed and see the pieces put in place as a reality. ITEM (Information Technology in Educational Management) should no longer be confined to the scope of School Information Systems or Computer Assisted School Administration. Educational management is, after all, for the support of learning and teaching, to make "the best schools, teachers, and courses available to all students without regard to gender, distance, resources, or disabilities" (Lake Oswego District Web Server, 1996). Confucius, thousands of years ago, had already highlighted such an educational ideal of "Teaching without discrimination". IT should be able to contribute in making this dream come true. Towards this goal, educational administrators and transformational leaders have to learn to ride with the wave of IT, and one can be sure that IT will not halt with just the Internet. Managing IT in education and for education will be a continual challenge to leaders in the schools of the future.

\section{REFERENCES}

Amdahl Corporation (1995) Intranet planning and management. On the $W W W$ at http://www. amdahl. com/

Asami, N. \& Kato, M. (1996) Cable TV begins 30-Mbit/s datacomm service. Nikkei Electronics Asia, May 1996.

IDC (1996) 1996: Year of the Internet ? Asia Computer Weekly, Jan 29 - Feb 4, 11-12.

EdWeb (1995) EdWeb Homeroom. On the WWW at http://k12.cnidr.org:90/

Giordano, V. (1996) The Internet: tool for transforming teaching and learning. Proceedings of the Thirteenth International Conference on Technology and Education, 1, 359-361.

Horizon (1996) Horizon Homepage. On the WWW at http://sunsite.unc.edu/horizon/

Itzkan, J. S. (1995) Assessing the future of telecomputing environments: Implications for instruction and administration. The Computing Teacher, Dec/Jan 1994-95, 60-64.

Lake Oswego District (1996) On the WWW at gopher://gopher.nrel.org:70/00/programs/ technology/plans/lakeoswego_plan 
NCREL (1966) Pathways to school improvement. On the $W W W$ at http://cedar.cic.net/ ncrel/sdrs/ pathwayg.htm

Wallis, C. (1995) The learning revolution. Times, Spring 1995, 49-51.

\section{BIOGRAPHIES}

Alex C.W. Fung received a B.Sc. in 1970 from the University of Hong Kong and Cert.Ed., Adv.Dip.Ed., and M.Ed. in subsequent years from the same university. He received his Ph.D. in educational management and administration in 1992 from the London University Institute of Education. He was a secondary school principal in Hong Kong for more than twenty years before he joined the Department of Education Studies of the Hong Kong Baptist University as senior lecturer in 1994. He is currently an associate professor and also Director of the School Administration and Management System Training \& Research Unit at the Hong Kong Baptist University.

S.W. Pun received a B.Sc. in 1972 from the Chinese University of Hong Kong and Dip. Ed. in subsequent years from the same university. He received his M.Ed. (Math Ed) in 1976 from the University of Georgia, USA and M.Sc.(Computing) in 1996 from the City University of Hong Kong. He was a secondary school computer teacher and principal in Hong Kong before he joined the Department of Science and Mathematics, Hong Kong Institute of Education in 1995. He is currently a senior lecturer in computer education and computer studies. 